\title{
The Chocolate Conching Technique and Its Impact on Physicochemical Properties: A Mini-Review
}

\author{
Rossi Indiarto $^{1}$, Edy Subroto ${ }^{2}$, Nandi Sukri ${ }^{3}$ \\ Department of Food Industrial Technology, Faculty of Agro-Industrial Technology, Universitas Padjadjaran, \\ Jl. Raya Bandung-Sumedang Km. 21, Jatinangor, Sumedang 45363, Indonesia \\ 1'rossi.indiarto@unpad.ac.id, ${ }^{2}$ edy.subroto@unpad.ac.id, ${ }^{3}$ nandi@unpad.ac.id
}

\begin{abstract}
Conching has been essential in the chocolate processing process because it results in a smooth choco mass with a distinctive aroma and taste. The process goes through three distinct phases: dry, pasty/ plastic, and liquid. Each of these stages affects the chocolate's flavor, flow properties, color, and texture. Variations in conching time and temperature resulted in differences in viscosity, texture, and flavor. Conching causes the solid particles to coat the fat phase, altering the chocolate's flow properties. The viscosity decreased as the sugar particle layer and cocoa mass increased, reducing particle interaction. The presence of components such as pyrazine, phenolic acid, and caffeine contributes to the flavor of chocolate. Meanwhile, volatile aromatic compounds and macromolecules such as carbohydrates and proteins degraded into amino acids influence the aroma of chocolate. Solid particles can be coated with the fat phase during conching to alter the chocolate's flow properties. Temp and conching duration parameters influence the chocolate's hardness. Furthermore, the oxidation and emulsification of tannins cause color changes. Conching effects on various physicochemical characteristics that affect the quality of chocolate, including flavor, flow properties, color, and texture., are discussed in this review.
\end{abstract}

Key words: Chocolate, cocoa, fat, flavor, rheology, viscosity

\section{INTRODUCTION}

Chocolate is a functional food that is world-famous due to its distinctive flavor and aroma. Chocolate is frequently consumed directly as a snack or as a standard option in chocolate-based food products such as bread, cakes, and various beverages. Behind the delectability, chocolate is demonstrated to be a complex multiphase system. Chocolate comprises solid particles like cocoa nibs, sugar, milk powder, and a continuous phase (cocoa butter, an emulsifier, or milk fat) [1]. Chocolate making involves a complex process to get good quality chocolate.
Cocoa nibs are the primary raw material used in chocolate production, and their quality determines the final satisfaction of the customers [2], [3]. Apart from raw materials and other supporting materials, processing techniques and particle size distribution significantly affect the physical, rheological properties, and organoleptic perceptions of chocolate [1].

Conching is a stage of chocolate production that is directly related to the chocolate's quality. This stage is also one of the most time-consuming in the chocolate-making process. Conching is a process that transforms a heterogeneous mixture of cocoa butter/ fat, sugar, and cocoa solids into a uniformly liquid [4]. Conching's primary function in chocolate production is to mechanically break down aggregates and reduce particle friction by combining a dispersing agent with a physical process, specifically friction and crush [4]. Conching is a critical process that ensures the chocolate mass has a fine texture and develops a distinct aroma and flavor. Variations in conching temperatures and times can result in various chocolate viscosities, textures, and flavors [5]. Thus, it is essential to discuss the effect of conching on physicochemical characteristics that determine the quality of chocolate, such as flavor, flow properties, color, and texture. This information will aid in producing high-quality chocolate.

\section{CHOCOLATE'S CONCHING PHASE}

Conching is a technique of chocolate processing in which a mixer and agitator, known as a conche, distributes the cocoa butter evenly and acts as a "scrub" of the particles [6]. It processes divided into three stages: dry, paste, and liquid. Cocoa nibs are mechanically crushed by a conche machine during the dry and paste phases. It will evaporate the material's water content and the undesirable volatile compounds from the cocoa beans. The relatively high temperature during the conching process also causes several chemical reactions resulting in chocolate flavor patterns. Low molecular weight volatile compounds, such as tetramethylpyrazine and benzaldehyde, are released. The presence of cocoa butter/ fat and an emulsifying agent in chocolate formulations aims to increase flowability. It is essential to reach the rheological properties requisite for tempering and molding. Lecithin is usually used as an 
Rossi Indiarto et al., International Journal of Emerging Trends in Engineering Research, 9(6), June 2021, 785 - 790

emulsifier in the chocolate industry. In the chocolate industry, lecithin is commonly used as an emulsifier. The dry phase of conching is critical to achieving good chocolate quality and is regarded as a crucial step in flavor development compared to the liquid phase [7], [8].

Conching is the final stage after mixing and refining. It is crucial in determining the viscosity, texture, and flavor of chocolate [9]. For a long time, this process can reduce particle size, evaporation of moisture, the release of volatile and acidic components, and oxidation to encourage the development of taste through heat generated by friction. The conching temperature varies according to the chocolate's formulation. The conching temperature varies depending on the chocolate's formulation. Conching dark chocolate can be done at a temperature of $70{ }^{\circ} \mathrm{C}$ and continued until it reaches $82{ }^{\circ} \mathrm{C}$. In milk chocolate, it is done at a temperature of $60{ }^{\circ} \mathrm{C}$ [10]. However, it chose a high heat of $<70{ }^{\circ} \mathrm{C}$ because it would be optimal to reduce the moisture content to $<0.5 \%$. In this condition, the cocoa butter is more liquid, which helps coat the particles and promotes the Strecker reaction [11], [12]. It saw the conching conditions for varying chocolate in Table 1.

Additionally, the conching temperature can be affected by the ingredients used in chocolate. Meanwhile, Engeseth and Ac Pangan [13] suggest keeping dairy chocolate products at less than $50{ }^{\circ} \mathrm{C}$ to prevent the Maillard. While conching lasts between 16 and 24 hours. Conching time, which is increasing, is undesirable because it affects process costs and increases temperature and mixing speed, affecting chocolate's flow properties [14].

Table 1. Conching conditions on various chocolate formulas

\begin{tabular}{llll}
\hline \hline Sample & $\begin{array}{l}\text { Conching } \\
\text { duration; temp }\end{array}$ & Conche & $\begin{array}{l}\text { Ref } \\
\text { - }\end{array}$ \\
\hline Milk chocolate & $12 \mathrm{hr} 10 \mathrm{~min}$ & $\begin{array}{l}\text { Double-overth } \\
\text { row }\end{array}$ & {$[9]$} \\
\hline $\begin{array}{l}\text { Fiber-enriched } \\
\text { milk chocolate }\end{array}$ & $15 \mathrm{hr} ; 60^{\circ} \mathrm{C}$ & $n m$ & {$[15]$} \\
\hline $\begin{array}{l}\text { Dark compound } \\
\text { chocolate }\end{array}$ & $6-8 \mathrm{hr} ; 55-60{ }^{\circ} \mathrm{C}$ & $n m$ & {$[16]$} \\
\hline $\begin{array}{l}\text { Composite meat } \\
\text { chocolate }\end{array}$ & $6 \mathrm{hr}$ & $\begin{array}{l}\text { Prestige wet } \\
\text { grinder }\end{array}$ & {$[17]$} \\
\hline $\begin{array}{l}\text { Dark chocolate } \\
\text { incorporation } \\
\text { with Sacha }\end{array}$ & $12 \mathrm{hr}$ & $\begin{array}{l}\text { Two-roller } \\
\text { refiner }\end{array}$ & {$[18]$} \\
$\begin{array}{l}\text { Inchi oil } \\
\text { Dark chocolate } \\
\text { from } \\
\text { reconstituted } \\
\text { cocoa liquor }\end{array}$ & $7.5 \mathrm{hr} ; 60{ }^{\circ} \mathrm{C}$ & Buhler conche & {$[19]$} \\
\hline $\begin{array}{l}\text { Reduced-sugar } \\
\text { chocolate }\end{array}$ & $21.5 \mathrm{hr} ; 50{ }^{\circ} \mathrm{C}$ & $\begin{array}{l}\text { Spectra 11 } \\
\text { Melanger }\end{array}$ & {$[20]$} \\
\hline $\begin{array}{l}\text { Dark chocolate } \\
\bullet\end{array}$ & $\begin{array}{l}\text { Dry phase: } 2 \mathrm{hr} ; \\
60{ }^{\circ} \mathrm{C} ; 1200 \\
\text { rpm }(\mathrm{clockwise}) \\
\text { and } 4 \mathrm{hr} ; 80{ }^{\circ} \mathrm{C} ;\end{array}$ & $\begin{array}{l}\text { Bühler } \\
\text { ELK'olino } \\
\text { conche }\end{array}$ & {$[21]$} \\
$1200 \mathrm{rpm}$ & & \\
\hline
\end{tabular}

\begin{tabular}{|c|c|c|c|}
\hline Sample & $\begin{array}{l}\text { Conching } \\
\text { duration; temp }\end{array}$ & Conche & $\begin{array}{l}\text { Ref } \\
\text {. }\end{array}$ \\
\hline & $\begin{array}{l}\text { (anti-clockwise) } \\
\text { - Liquid phase: } \\
15 \text { min; } 45^{\circ} \mathrm{C} \text {; } \\
2400 \\
\text { (clockwise) and } \\
15 \text { min } \\
\text { (anti-clockwise) }\end{array}$ & & \\
\hline
\end{tabular}

$n m=$ not mentioned

\section{CONCHING'S EFFECT ON THE PHYSICOCHEMICAL PROPERTIES OF CHOCOLATE}

\subsection{Flavors' quality}

Flavors are critical components in determining the quality of chocolate produced. Several alkaloids, including phenolic, theobromine, caffeine, pyrazine, peptides, and free amino acids, influence the flavor. Additionally, tannin and polyphenol components contribute to the harsh and bitter chocolate [22]. The bitterness of the cocoa develops or becomes more pronounced during the drying and roasting processes, which begin with fermentation and continue through drying and roasting [23].

The aroma of chocolate is affected by macromolecules such as carbohydrates and proteins degraded to an amino acid. Chocolate's aroma is highly complex chemically due to polar and non-polar compounds like hydrocarbons, ketones, aldehydes, alcohol, furanones, esters, acids, and pyrazines [24]. Sugar affects how pyrazine compounds and several volatile components that impart flavor to chocolate-based food products are formed. According to Khairy et al. [25], it is necessary to consider the effect of the fat phase on the release of aromas in the oral cavity concerning volatile and non-volatile compounds. Numerous aspects influence the development of chocolate flavor, including precursors, cocoa bean genotype, soil conditions, environmental influences, fermentation methods, drying techniques, roasting, and conching. Conching is crucial to the formation of chocolate's flavor profile. Conching can remove excess moisture and volatile compounds from particles and reduce their size [13], [26]. So, it can result in the formation of specific components.

Excluding non-volatile acids like lactic, tartaric, succinic, citric, and oxalic acids, the volatile acid compounds of cocoa beans decreased significantly during roasting. However, as roasting time increases, the pyrazine concentration rises [25], [27]. The more time it takes to process the cocoa beans, the more intensely colored they will be. It is due to the material's Maillard reaction. This reaction is necessary for forming aldehyde and pyrazine compounds, which also significantly impact chocolate taste [22], [24]. This reaction also occurs during conching as a result of the generated heat. Maillard reactions occur in milk protein and lactose during the manufacturing of milk chocolate. Short-chain peptides and amino acids are frequently linked to 
the chocolate flavor as precursors. It is necessary to modify the properties of peptides and free amino acids derived from various raw materials during conching. Conching produces a distinct chocolate aroma. It results in changes to the pyrazine, a volatile, heterocyclic nitrogen component [28]. The pyrazine group is a volatile substance that contributes to the flavor of chocolate [24]. Tetramethylpyrazine plays a critical role in developing chocolate's aroma [29]. Numerous factors, including weather, maturity level, and cocoa variety, can affect pyrazine levels [30].

While it can remove undesirable volatile components through conching, the flavoring components that give chocolate its distinctive flavor must be protected. Significant variables affecting the machine's operation, such as temperature, time, and shear effects, are adjusted according to the processed chocolate formula. Excessive conching causes aromatic compounds to evaporate quickly [31]. Each component's evaporation rate varies depending on the material [32], [33]. However, the concentration of the majority of compounds that contribute to aroma decreases, particularly in the fat phase, and tends to be constant in the water-soluble phase.

\subsection{Rheological properties}

Another important factor used by reference to evaluate the process and product quality are chocolate's rheological properties. These characteristics impact the overall product's quality and stability viscosity, consistency, taste, and aroma perception in the mouth [34]. Deformation and errors during the processing process, particularly those associated with molding, are directly related to the rheological and other properties of the product, which can result in production losses.

Chocolate's rheological properties are influenced by formulation (type and concentration of fat or emulsifier) and processing (refining, conching, and tempering) [35], [36]. Conching coats the solid particles in a fat phase, altering the chocolate's flow characteristics. Conching can reduce chocolate's viscosity by reducing its moisture content during processing, thereby altering its rheological properties. To minimize the detrimental effect of moisture on these properties, it is generally necessary to select a high-quality raw material and control conching conditions.

The coating of sugar and cocoa particles thickens as fat and lecithin are added during the conching process. As the layer thickness increases, the interaction between one particle and other particles decreases, lowering the viscosity value [36]. High temperatures conching reduce the yield stress and viscosity. Due to the large gap between the solid aggregates, cocoa butter can become immobilized. Chocolate's rheological properties are significantly affected by the amount of immobilized cocoa butter. Conching of agglomerated particles results in structural and quantitative changes that affect their resistance to melting. The existence of lecithin, fat, and emulsification influence chocolate melting [36]. Lecithin and cocoa butter residue added at the end of the conching give the chocolate a lubricating effect.
The onset of the lubricating effect is accompanied by an increase in particle mobility, decreased particle interaction, and reduced viscosity. The addition of the two materials alters the flow properties of the chocolate mass by reducing particle aggregation and interactions between particles. When the moisture content is insufficient to evaporate during the initial stages of conching, an emulsifier such as polyglycerol polyricinoleate (PGPR) must be added. It is intended that the water content of the mixture remains stable and does not adversely affect the chocolate's rheological properties [37].

\subsection{Color properties}

Conching affects the color change of the resulting chocolate [8], [37]. Its changes occur because of the tannin's oxidation and emulsification. Prawira and Barringer [8] examined the impact of conching time on milk chocolate formulations. They reported that the extended conching time decreased particle size perceptions and produced more vibrant chocolate that consumers preferred.

Chocolate contains tannin compounds that are most effective between $60-80{ }^{\circ} \mathrm{C}$. If the conching process is performed at a temp higher than the effective temp, the tannins' work will be impaired, as will other properties. Organoleptic testing of the taste, color, smell, and texture of chocolate demonstrates that the color produced by conching depends on each cocoa bean origin's roasting and conching times [5].

\subsection{Textural properties}

Hardness is the primary factor affecting the texture of chocolate. Fat and sugar content, particle distribution, tempering process conditions, and conching temperature are factors to consider in chocolate hardness [38], [39]. The coating of solid particles with fat components affects the smooth texture [12]. Temperature and conching time combinations affect the properties of the resulting texture [8]. Chocolate's texture has an impact on taste perception. It can cover up chocolate's distinctive taste due to its melting and unsuitable texture [40].

Melting chocolate in the mouth occurs due to the cocoa butter melting due to the body's temperature. Melting alters the structure of the food as it is masticated. The dynamic process of melting chocolate in the mouth involves a phase transition from a solid-state at ambient temperature to a smooth solid suspension at body temperature. Chocolate melts in the mouth, mixes with saliva, and undergoes a phase change when consumed [41]. Melting chocolate at body temperature indicates that the cocoa butter crystals are in the $\mathrm{V}$ form. It forms the most stable and is obtained through the proper tempering process. It also has a melting point of approximately $34{ }^{\circ} \mathrm{C}$ [35]. When the chocolate enters the mouth, this condition causes it to begin melting. The organoleptic properties of chocolate are highly dependent on the properties of cocoa butter as a continuous phase [42], [43]. The hardness level and the size of the chocolate particles will both decrease during the oral process. As particle size decreases, the surface area available for heat transfer 
increases [44]. This process results in a breakdown of the formation of chocolate particles, which intensifies the melting process of chocolate.

\section{CONCLUSION}

Conching is a critical process that affects the flavor, texture, color, and flow properties of chocolate. The conching is divided into three phases: dry, pasty, and liquid. The combination of temperature and conching time affects the chocolate's hardness. Conching for an extended time was shown to result in a lighter brown color that consumers prefer. Numerous components contribute to the flavor of chocolate, including phenolic acids, caffeine, and others. Additionally, ingredients such as aromatic compounds and carbohydrates can influence the aroma produced by chocolate.

\section{ACKNOWLEDGEMENT}

The authors gratefully acknowledge Universitas Padjadjaran and the Republic of Indonesia's Ministry of Education, Culture, Research, and Technology for their funding support.

\section{REFERENCES}

[1] M. El-kalyoubi, M. F. Khallaf, A. Abdelrashid, and E. M. Mostafa, "Quality characteristics of chocolate Containing some fat replacer," Ann. Agric. Sci., vol. 56, no. 2, pp. 89-96, 2011, doi: 10.1016/j.aoas.2011.05.009.

[2] M. A. Quelal-Vásconez, M. J. Lerma-García, É. Pérez-Esteve, P. Talens, and J. M. Barat, "Roadmap of cocoa quality and authenticity control in the industry: A review of conventional and alternative methods," Compr. Rev. Food Sci. Food Saf., vol. 19, no. 2, pp. 448-478, Mar. 2020, doi: 10.1111/1541-4337.12522.

[3] R. Indiarto, Y. Pranoto, U. Santoso, and . S., "Evaluation of Physicochemical Properties and Antioxidant Activity of Polyphenol-Rich Cacao Bean Extract Through Water Blanching," Pakistan J. Nutr., vol. 18, no. 3, pp. 278-287, 2019, doi: 10.3923/pjn.2019.278.287.

[4] E. Blanco et al., "Conching chocolate is a prototypical transition from frictionally jammed solid to flowable suspension with maximal solid content," Proc. Natl. Acad. Sci. U. S. A., vol. 116, no. 21, pp. 10303-10308, May 2019, doi: 10.1073/pnas.1901858116.

[5] M. Torres-Moreno, A. Tarrega, E. Costell, and C. Blanch, "Dark chocolate acceptability: Influence of cocoa origin and processing conditions," J. Sci. Food Agric., vol. 92, no. 2, pp. 404-411, Jan. 2012, doi: 10.1002/jsfa.4592.

[6] G. Vivar-Vera, B. Torrestiana-Sanchez, J. A. Monroy-Rivera, and E. Brito-De La Fuente, "Chonching - Rheological and structural changes of chocolate mass," Dtsch. Leb., vol. 104, no. 8, pp. 376-382, Aug. 2008.

[7] a Fischer, T. Abubaker, a Hasselbarth, and F. Ullrich, "Understanding the impact of conching on chocolate flavour using a combination of instrumental flavour analysis and tasting techniques.," in Expression of Multidisciplinary Flavour Science (12th Weurman Symposium), 2008, pp. 309-312, [Online]. Available: $\% 5 \mathrm{C} \% 5 \mathrm{CRobsrv}-05 \% 5 \mathrm{Creference}$ manager\%5CArticles\%5C13016.pdf.

[8] M. Prawira and S. A. Barringer, "Effects of conching time and ingredients on preference of milk chocolate," J. Food Process. Preserv., vol. 33, no. 5, pp. 571-589, Oct. 2009, doi: 10.1111/j.1745-4549.2008.00272.x.

[9] V. Glicerina, F. Balestra, M. Dalla Rosa, and S. Romani, "Effect of manufacturing process on the microstructural and rheological properties of milk chocolate," J. Food Eng., vol. 145, pp. 45-50, 2015, doi: 10.1016/j.jfoodeng.2014.06.039.

[10] A. C. Aprotosoaie, S. V. Luca, and A. Miron, "Flavor Chemistry of Cocoa and Cocoa Products-An Overview," Compr. Rev. Food Sci. Food Saf., vol. 15, no. 1, pp. 73-91, 2016, doi: https://doi.org/10.1111/1541-4337.12180.

[11] S. Bolenz, A. Manske, and M. Langer, "Improvement of process parameters and evaluation of milk chocolates made by the new coarse conching process," Eur. Food Res. Technol., vol. 238, no. 5, pp. 863-874, May 2014, doi: 10.1007/s00217-014-2165-4.

[12] M. S. Jolly, S. Blackburn, and S. T. Beckett, "Energy reduction during chocolate conching using a reciprocating multihole extruder," J. Food Eng., vol. 59, no. 2-3, pp. 137-142, 2003, doi: 10.1016/S0260-8774(02)00443-0.

[13] N. J. Engeseth and M. F. Ac Pangan, "Current context on chocolate flavor development - a review," Curr. Opin. Food Sci., vol. 21, pp. 84-91, 2018, doi: 10.1016/j.cofs.2018.07.002.

[14] R. P. Aidoo, N. De Clercq, E. O. Afoakwa, and K. Dewettinck, "Optimisation of processing conditions and rheological properties using stephan mixer as conche in small-scale chocolate processing," Int. J. Food Sci. Technol., vol. 49, no. 3, pp. 740-746, Mar. 2014, doi: 10.1111/ijfs. 12360.

[15] A. B. Verde, I. D. Alvim, V. Luccas, and R. M. Vercelino Alves, "Stability of milk chocolate with hygroscopic fibers during storage," Lwt, vol. 137, no. October 2020, p. 110477, 2021, doi: 10.1016/j.lwt.2020.110477.

[16] S. T. Talawar, R. Chetana, B. S. Roopa, and G. Suresh Kumar, "Effect of wheat bran oil concentrates on quality and nutrition of WBO dark compound chocolates," Lwt, vol. 142, no. February, p. 111005, 2021, doi: 10.1016/j.lwt.2021.111005.

[17] M. Kaur, S. Kumar, Z. F. Bhat, A. E.-D. A. Bekhit, and M. A. Bhatti, "Development of composite meat chocolate fortified with calcium and plant extracts," Food Biosci., vol. 42, no. April, p. 101082, 2021, doi: 10.1016/j.fbio.2021.101082.

[18] M. Medina-Mendoza et al., "Rheological, bioactive properties and sensory preferences of dark chocolates 
Rossi Indiarto et al., International Journal of Emerging Trends in Engineering Research, 9(6), June 2021, 785 - 790

with partial incorporation of Sacha Inchi (Plukenetia volubilis L.) oil," Heliyon, vol. 7, no. 2, 2021, doi: 10.1016/j.heliyon.2021.e06154.

[19] M. Puchol-Miquel, C. Palomares, J. M. Barat, and É. Perez-Esteve, "Formulation and physico-chemical and sensory characterisation of chocolate made from reconstituted cocoa liquor and high cocoa content," $L W T$, vol. 137, p. 110492, 2021, doi: https://doi.org/10.1016/j.1wt.2020.110492.

[20] T. Aaltonen, E. Kytö, S. Ylisjunttila-Huusko, and M. Outinen, "Effect of the milk-based ash-protein ratio on the quality and acceptance of chocolate with a reduced sugar content," Int. Dairy J., vol. 105, p. 104663, 2020, doi: https://doi.org/10.1016/j.idairyj.2020.104663.

[21] M. Hinneh et al., "Pod storage with roasting: A tool to diversifying the flavor profiles of dark chocolates produced from 'bulk' cocoa beans? (Part II: Quality and sensory profiling of chocolates)," Food Res. Int., vol. 132, p. 109116, 2020, doi: https://doi.org/10.1016/j.foodres.2020.109116.

[22] A. C. Aprotosoaie, S. V. Luca, and A. Miron, "Flavor Chemistry of Cocoa and Cocoa Products-An Overview," Compr. Rev. Food Sci. Food Saf., vol. 15, no. 1, pp. 73-91, 2016, doi: 10.1111/1541-4337.12180.

[23] D. Żyżelewicz, W. Krysiak, J. Oracz, D. Sosnowska, G. Budryn, and E. Nebesny, "The influence of the roasting process conditions on the polyphenol content in cocoa beans, nibs and chocolates," Food Res. Int., vol. 89, pp. 918-929, 2016, doi: 10.1016/j.foodres.2016.03.026.

[24] S. C. G. N. Braga et al., "Study of volatile profile in cocoa nibs, cocoa liquor and chocolate on production process using GC $\times$ GC-QMS," Microchem. J., vol. 141, pp. 353-361, 2018, doi: 10.1016/j.microc.2018.05.042.

[25] H. L. Khairy, A. F. Saadoon, W. Zzaman, T. A. Yang, and A. Mat Easa, "Identification of flavor compounds in rambutan seed fat and its mixture with cocoa butter determined by SPME-GCMS," J. King Saud Univ. Sci., vol. 30, no. 3, pp. 316-323, 2018, doi: 10.1016/j.jksus.2017.03.001.

[26] A. Caligiani, A. Marseglia, and G. Palla, "Cocoa: Production, Chemistry, and Use," B. Caballero, P. M. Finglas, and F. B. T.-E. of F. and H. Toldrá, Eds. Oxford: Academic Press, 2016, pp. 185-190.

[27] S. Jinap, W. R. Wan Ishak, R. Abdul Rahman, and L. Nordin, "Effect of roasting time and temperature on volatile component profile during nib roasting of cocoa beans (Theobroma cacao)," J. Sci. Food Agric., vol. 77, pp. 441-448, Aug. 1998, doi: 10.1002/(SICI)1097-0010(199808)77:4<441::AID-JSF A46>3.0.CO;2-\#.

[28] M. Owusu, M. A. Petersen, and H. Heimdal, "Effect of fermentation method, roasting and conching conditions on the aroma volatiles of dark chocolate," J. Food Process. Preserv., vol. 36, no. 5, pp. 446-456, Oct. 2012, doi: 10.1111/j.1745-4549.2011.00602.x.

[29] E. O. Afoakwa, A. Paterson, M. Fowler, and A. Ryan,
"Flavor Formation and Character in Cocoa and Chocolate: A Critical Review," Crit. Rev. Food Sci. Nutr., vol. 48, pp. 840-857, Nov. 2008, doi: 10.1080/10408390701719272.

[30] I. M. da V. Moreira, L. de F. Vilela, C. Santos, N. Lima, and R. F. Schwan, "Volatile compounds and protein profiles analyses of fermented cocoa beans and chocolates from different hybrids cultivated in Brazil," Food Res. Int., vol. 109, pp. 196-203, 2018, doi: 10.1016/j.foodres.2018.04.012.

[31] M. Owusu, M. A. Petersen, and H. Heimdal, "Effect of fermentation method, roasting and conching conditions on the aroma volatiles of dark chocolate," J. Food Process. Preserv., vol. 36, no. 5, pp. 446-456, 2012, doi: 10.1111/j.1745-4549.2011.00602.x.

[32] R. Indiarto and B. Rezaharsamto, "A review on ohmic heating and its use in food," Int. J. Sci. Technol. Res., vol. 9, no. 2, pp. 485-490, 2020.

[33] R. Indiarto and M. A. H. Qonit, "A review of irradiation technologies on food and agricultural products," Int. J. Sci. Technol. Res., vol. 9, no. 1, pp. 4411-4414, 2020.

[34] V. Glicerina and S. Romani, "Advances in Yield Stress Measurements for Chocolate," Advances in Food Rheology and Its Applications. Woodhead Publishing Limited, pp. 459-481, 2017, doi: 10.1016/B978-0-08-100431-9.00018-8.

[35] V. A. Fernandes, A. J. Müller, and A. J. Sandoval, "Thermal, structural and rheological characteristics of dark chocolate with different compositions," J. Food Eng., vol. 116, no. 1, pp. 97-108, 2013, doi: 10.1016/j.jfoodeng.2012.12.002.

[36] V. Glicerina, F. Balestra, M. D. Rosa, and S. Romani, "Rheological, textural and calorimetric modifications of dark chocolate during process," J. Food Eng., vol. 119, no. 1 , pp. 173-179, 2013, doi: 10.1016/j.jfoodeng.2013.05.012.

[37] S. Bolenz, T. Thiessenhusen, and R. Schäpe, "Fast conching for milk chocolate," Eur. Food Res. Technol., vol. 218, no. 1, pp. 62-67, 2003, doi: 10.1007/s00217-003-0790-4.

[38] J. Tan and B. M. Balasubramanian, "Particle size measurements and scanning electron microscopy (SEM) of cocoa particles refined/conched by conical and cylindrical roller stone melangers," J. Food Eng., vol. 212, pp. 146-153, 2017, doi: 10.1016/j.jfoodeng.2017.05.033.

[39] N. Konar, "Influence of conching temperature and some bulk sweeteners on physical and rheological properties of prebiotic milk chocolate containing inulin," Eur. Food Res. Technol., vol. 236, no. 1, pp. 135-143, 2013, doi: 10.1007/s00217-012-1873-x.

[40] S. P. Breen, N. M. Etter, G. R. Ziegler, and J. E. Hayes, "Oral somatosensatory acuity is related to particle size perception in chocolate," Sci. Rep., vol. 9, no. 1, p. 7437, 2019, doi: 10.1038/s41598-019-43944-7.

[41] A. M. Carvalho-da-Silva, I. Van Damme, W. Taylor, J. Hort, and B. Wolf, "Oral processing of two milk 
Rossi Indiarto et al., International Journal of Emerging Trends in Engineering Research, 9(6), June 2021, 785 - 790

chocolate samples.," Food Funct., vol. 4, no. 3, pp. 461-469, Feb. 2013, doi: 10.1039/c2fo30173c.

[42] A. M. Torbica, B. S. Pajin, R. P. Omorjan, I. S. Lončarević, and J. M. Tomić, "Physical Properties of Chocolate with Addition of Cocoa Butter Equivalent of Moderate Hardness," J. Am. Oil Chem. Soc., vol. 91, no. 1, pp. 39-48, 2014, doi: 10.1007/s11746-013-2357-2.

[43] M. Medina-Mendoza et al., "Rheological, bioactive properties and sensory preferences of dark chocolates with partial incorporation of Sacha Inchi (Plukenetia volubilis L.) oil," Heliyon, vol. 7, no. 2, p. e06154, 2021, doi: https://doi.org/10.1016/j.heliyon.2021.e06154.

[44] T.-A. L. Do, J. Hargreaves, B. Wolf, J. Hort, and J. Mitchell, "Impact of Particle Size Distribution on Rheological and Textural Properties of Chocolate Models with Reduced Fat Content," J. Food Sci., vol. 72, pp. E541-52, Dec. 2007, doi: 10.1111/j.1750-3841.2007.00572.x. 